\title{
Does the care dependency of nursing home residents influence their health-related quality of life?-A cross-sectional study
}

\author{
Manuela Tabali ${ }^{1}$, Thomas Ostermann ${ }^{2 *}$, Elke Jeschke ${ }^{3}$, Theo Dassen ${ }^{1}$ and Cornelia Heinze ${ }^{4}$
}

\begin{abstract}
Background: Studies on health-related quality of life (HRQOL) are missing for nursing home residents independent from their health conditions or interventions after admission. Our aim was to analyse if the care dependency of nursing home residents influence their HRQOL and to describe HRQOL of nursing home residents at the time of admission.
\end{abstract}

Method: Eleven German nursing homes were randomly selected for a cross-sectional multicentre study from April 2008 until December 2009. HRQOL was measured with the Nottingham Health Profile (NHP) in the six domains "Physical Mobility", "Energy", "Pain", "Social Isolation", "Emotional Reaction" and "Sleep". Domain scores range from zero (good subjective health status) to 100 (poor subjective health status). Care dependency was evaluated using the Care Dependency Scale, age, sex, cognitive status and diseases were documented by the research assistants. Multivariate regression analysis was performed to quantify the influence of care dependency on HRQOL.

Results: 120 residents were included in total. HRQOL was mostly reduced in the domains "Physical Mobility" and "Energy" (mean scores >43.0), while impairment differences in the domains "Pain", "Social Isolation", "Emotional Reaction" and "Sleep" were only moderate $(\leq 25.0)$. HRQOL was not influenced by the age. Women $(n=85)$ had a significantly poorer HRQOL in the domain "Pain" than men (mean score women: $29.5 \pm 31.5$; males: $14.9 \pm 17.2$; $p=0.011)$. Care dependency had an influence on the domain "Sleep" ( $B=-0.195, p=0.031$ ), while the other domains were not influenced by care dependency. Residents with a low care dependency scored significantly lower (better HRQOL) in the domain "Sleep" than residents with a high care dependency (mean score 15.3; SD \pm 19.0 versus mean score $32.8 \mathrm{SD} \pm 33.2 ; \mathrm{p}<0.02$ ).

Conclusion: The level of care dependency has no influence on the HRQOL from the nursing home residents' perspective apart from the domain "Sleep". High care dependency residents have a lower HRQOL in the domain "Sleep" compared to moderate and low care dependency residents. We found a significantly lower HRQOL in women compared to men in the domain "Pain".

Keywords: Heath-related quality of life, Care dependency, Nursing home residents

\footnotetext{
* Correspondence: thomas.ostermann@uni-wh.de

${ }^{2}$ Institute for Integrative Medicine, University of Witten/Herdecke, Gerhard-Kienle-Weg 4, Herdecke 58313, Germany

Full list of author information is available at the end of the article
} 


\section{Background}

The average age of OECD country populations is increasing. As a consequence, the oldest population cohort grows fastest. The population aged 80 years and above has the most pronounced need for care, which is for example provided in nursing homes [1]. Nursing homes provide the majority of institutional care for elderly people with a need of care, which could not be met when living at home [2]. In Europe between two and ten percent of the elderly people live in nursing homes [3,4]. Within Europe, Germany is currently one of the four countries with the oldest population and is exceeded worldwide only by Japan [5]. In Germany four percent of the people aged 65 years and above live in nursing homes, with $49 \%$ of them being older than 85 years. In 2007 there were a total of 2.25 million care dependent persons, which was an increase of $6 \%$ compared to the year 2005 [6].

Care dependency has been described as: "The professional support to a patient whose self-care abilities have decreased and whose care demands make him/her to a certain degree dependent. The aim of the support is to restore the patient's independency in performing self care" [7]. Care dependency residents are mostly in need of help with basic activities of daily living over an extended period of time, like bathing, dressing, eating and moving around. Thus, the needs of residents are due to long-term chronic and multimorbid conditions, which cause physical and/or mental disabilities and may influence their health-related quality of life (HRQOL) [8] and finally lead to a high degree of care dependency $[9,10]$.

HRQOL has been defined as an individual's subjective experience of the impact that illnesses and their treatments have on the individual's functioning in a variety of domains such as physical, psychological and social functioning as well as the impact of illnesses on the ability to engage in activities of daily living [11]. HRQOL scores might therefore be interpreted as reflections of the resident's own experience of gained (or lost) HRQOL and provide a non-disease specific outcome measure [12].

HRQOL is one of the most frequently used indicators to assess outcome for health care programs i.e. in rehabilitation medicine and in evaluating the health status of elderly people.

Only some studies have investigated the influence of care dependency and HRQOL without getting a clear picture. While Gonzales- Salvador et al. [13] found a significantly reduced quality of life in residents/patients with high care dependency, a study of Menzi-Kuhn [14] in Switzerland did not find a correlation between care dependency and HRQOL. In Germany, no study has investigated the influence of care dependency and HRQOL so far.

Therefore the following research questions were addressed in the current study:
1. Does the care dependency of nursing home residents influence their health-related quality of life of ?

2. What is the health-related quality of life of nursing home residents at the time of their admission?

\section{Methods}

\section{Study design}

The present study was designed as a cross-sectional study nested in the project "Health-related quality of life of residents in nursing homes in Germany", which aims at evaluating the HRQOL with regard to pressure ulcer, falls, incontinence, care dependency and structural factors of the nursing homes such as staff qualification and activities provided for the residents. Ethical approval was given by the Ethical Committee of the Charité-University Medicine Berlin, (No: EA1/212/07).

\section{Setting and participants}

Eleven nursing homes with a minimum of 50 beds out of 288 in Berlin and Brandenburg were randomly selected for this study. A total of 553 residents newly admitted to the nursing homes, or their legal advocates, were informed of the project. Inclusion criterion was the written informed consent given by the nursing home resident or the relevant legal advocate within the first two weeks upon nursing home admission. Residents were excluded if they were in a final stage of life with a survival probability of less than four weeks, in shortterm care with a planned stay of less than four weeks and had a severe cognitive impairment.

\section{Questionnaire}

Health-related quality of life was measured with the Nottingham Health Profile (NHP). The NHP was designed to be a standardized and simple measuring instrument of the subjective health status in the physical, social and emotional domains. It was validated in different settings and up to day translated into 22 languages [15]. It has proven its feasibility for nursing home residents with normal cognitive function and moderate cognitive impairment [16].

The German validated version of the NHP consists of 38 items in six domains; "Energy" (3 items), "Pain" (8 items), "Emotional Reactions" (9 items), "Sleep" (5 items), "Social Isolation" (5 items) and "Physical Mobility" (8 items). The items are answered by "yes" if the statement adequately reflected his /her current status or feeling or by "no" otherwise. Positive responses were weighted based on Thurstone's Method of Paired Comparisons. Negative responses were not weighted. The values of all statements belonging to the domain were added up and thus produced the domain total. Domain scores range from zero (good subjective health status) to 100 (poor subjective health status) [17]. 
For our purpose and in agreement with the German author Kohlmann the NHP was modified to questions. For instance, the original statement "Everything is an effort." in our study was changed into "Is everything an effort for you?". The modified version was previously tested and showed acceptable results [18].

Care dependency was evaluated using the Care Dependency Scale (CDS), which is based on Henderson's theory and consists of 15 items and includes various physical and psychosocial items (e.g. mobility, hygiene, nutrition, communication, sense of rules and values). The CDS fulfils the quality criteria for psychometric tests and has up to day been translated into 12 languages [10]. It is widely used in the field of geriatric and geronto-psychiatric research [19] and has been validated in long-term care populations [10]. Scores can range from 15 (high care dependency) to 75 (no care dependency). Score values can be categorized into "low care dependency" (60 to 75 points), moderate care dependency (45 to 59 points) and high care dependency (15 to 44 points) [20].

\section{Data collection}

The recruitment period lasted from April 2008 until December 2009. The data collection was performed by trained research assistants. The modified NHP was collected in the second week upon nursing home admission in the resident's room. Where the resident was unable to complete the NHP independently due to visual or other physical impairments, NHP interviews were conducted by research assistants. If the resident was unable to answer the questions, for example if he/she could not communicate with the research assistant or was disoriented and talked about other things than those asked, the NHP was not collected.

Care dependency of each resident was collected from the responsible nurse. The resident's age, sex, cognitive status and diseases were documented by the research assistants using a machine-readable data form.

The cognitive status of each resident was evaluated using the Mini-Mental State Examination (MMSE) with scores ranging from 0 (very severe cognitive impairment) to 30 (no cognitive impairment). The MMSE is widely used and has been validated in long-term care populations, such as nursing homes $[21,22]$.

Diseases of the residents were recorded from the patient's file using the chapters of the International Classification of Diseases (ICD-10) [23].

All completed forms were scanned, evaluated, verified and exported to a database.

\section{Statistical analysis}

Demographic variables were analyzed using descriptive statistics. Continuous variables were summarized using mean and standard deviation (SD). In the case of nominal variables comparisons between groups were made using the Chi-square Test. In case of continuous variables group differences were evaluated using t-test (for 2 groups) or one factorial analysis of variance (for more than two groups). Multivariate regression analysis was performed to quantify the influence of care dependency on HRQOL. Therefore, the six domains of the NHP were considered as dependent variables, while CDS scores together with age and gender were considered to be independent variables. Due to a low number of missing values we in accordance with Donner [24] decided to replace missing values of the CDS with mean values. To allow for comparisons between the six domains, the standardized regression coefficients $B$ and p-values were calculated. Autocorrelation was determined by Durbin-Watson statistics, whereby test-statistics between 1.5 and 2.5 indicate no serious autocorrelation. Model quality and accuracy was assessed using determination coefficient $\mathrm{R}^{2}$ [25]. The complete statistical analysis was performed with IBM SPSS Statistics 19.0 for Windows.

\section{Results \\ Sample}

From a total of 553 newly administered residents, 120 residents were included in the present analysis after checking for inclusion and exclusion criteria (Figure 1). The mean age of residents was 84.0 years ( $\mathrm{SD} \pm 8.4$ ), with $45.0 \%(n=54)$ of the study participants aged younger than 85 years. Most of the residents in our study were female $(70.8 \%, \mathrm{n}=85) .12 .5 \%(\mathrm{n}=15)$ were single, $65.0 \%(n=78)$ were widowed and $22.5 \%(n=27)$ were married or were in a steady relationship with a partner.

Prior to nursing home admission $43.3 \%(n=52)$ of the residents had lived at home, $45.8 \%(n=55)$ had been in hospitals or in long-term care institutions and $10.9 \%$ ( $n=13)$ in other situations. Most of the residents were suffering from diseases of the circulatory system $(n=98$; $81.7 \%)$, followed by mental and behavioural disorders ( $\mathrm{n}=69 ; 57.5 \%)$, endocrine, nutritional and metabolic diseases $(n=61 ; 50.8 \%)$, diseases of the musculoskeletal system and connective tissue $(n=57 ; 47.5 \%)$, and diseases of the genitourinary system $(n=53 ; 44.2 \%)$. Eighty-two percent of the residents $(n=99)$ were diagnosed with three or more diseases.

Care dependency was determined in $92.5 \%(\mathrm{n}=111)$ of the residents with a mean of $53.9(\mathrm{SD} \pm 11.9)$ in the CDS. The group of residents in which care dependency values were missing $(n=9)$ did not differ with regard to age (84.2 years; $\mathrm{SD} \pm 8.6 ; \mathrm{p}=0.327$ ) and gender (women $\mathrm{n}=7 ; \mathrm{p}=0.634$ ) from the group of residents in which care dependency was determined.

A total of $30.8 \%(n=37)$ had a low care dependency, $42.5 \%(\mathrm{n}=51)$ had a moderate care dependency and $19.2 \%(n=23)$ had a high care dependency. 


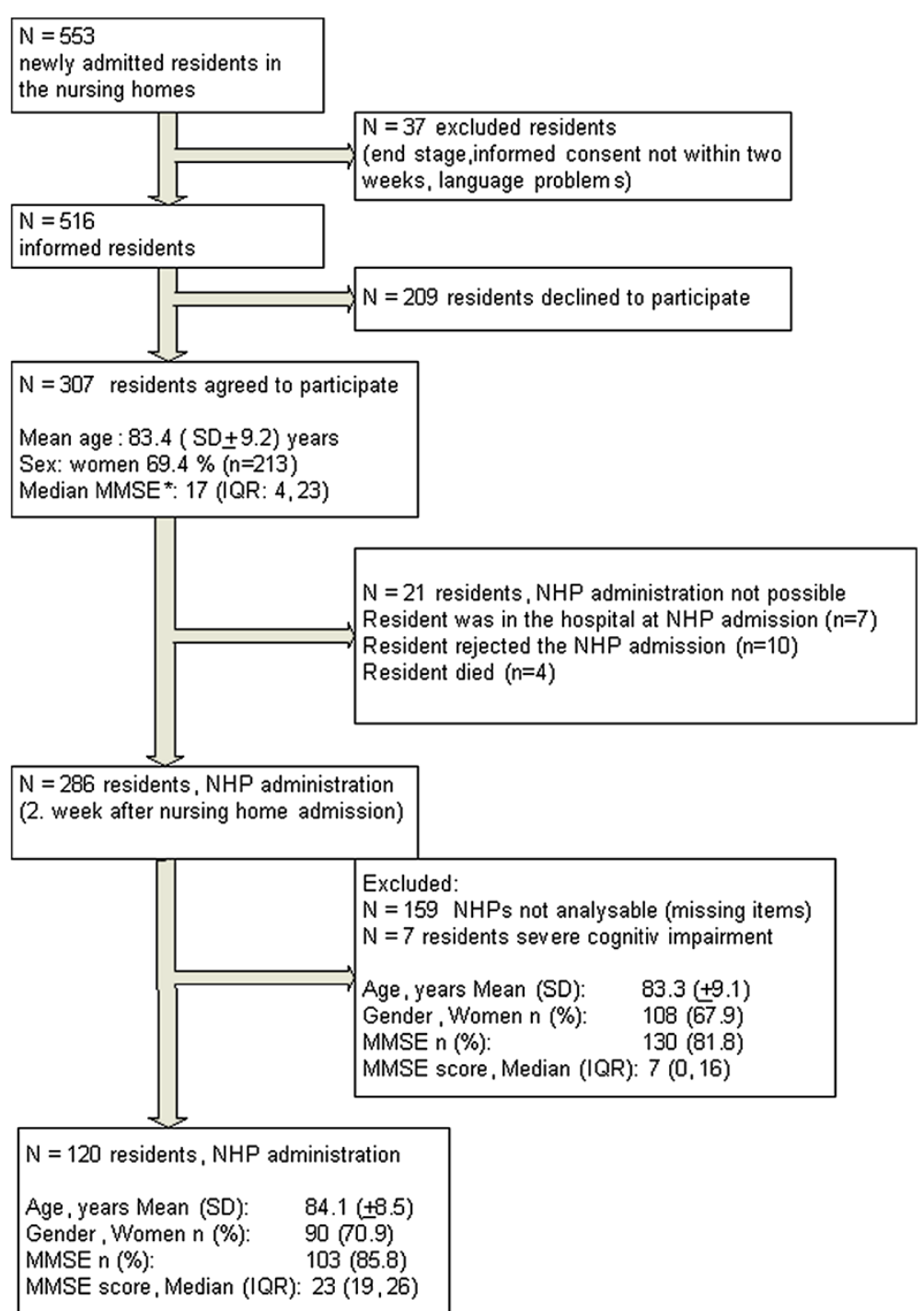

Figure 1 Study population. $\mathrm{NHP}=$ Nottingham Health Profile. MMSE = Mini-Mental State Examination.

\section{Health-related quality of life}

HRQOL was measured in the domains "Energy", "Pain", "Emotional Reactions", "Sleep", "Social Isolation" and "Physical Mobility" with domain scores ranging from zero (good subjective health status) to 100 (poor subjective health status).

The domain "Emotional Reaction" had the lowest mean scores of all the NHP domains with 19.2 (SD \pm 22.7$)$. The questions most frequently answered with "yes" in this domain were "Things are getting me down" $(40.0 \%$; $n=48)$. $30.8 \%(\mathrm{n}=37)$ answered all nine questions about "Emotional Reaction" with "no". Only one resident answered all questions with "yes".

The second lowest score of the NHP was noticed in the domain "Sleep" (mean 22.0; SD \pm 27.0 ), with "I' $\mathrm{m}$ waking up in the early hours of the morning" being most frequently answered with "yes" $(40.0 \% ; n=48)$. Overall, $60.8(n=73)$ of the residents answered at least one out of five sleep questions with yes. Three residents answered all question with "yes".

The domain "Social Isolation" is placed on the third position of all NHP domains with a mean score of 22.4 $(\mathrm{SD} \pm 26.3)$. The question most frequently answered with "yes" was "I feel lonely" $(36.7 \% ; n=44) .39 .2 \%(n=47)$ of the residents had no problems with "Social Isolation" and answered all question in this domain with "no". Three residents answered all questions with "yes".

The domain "Pain" followed on the fourth position of the NHP domains with a mean score of $25.2 \pm 28.8$. The questions in this domain that the residents most frequently answered with "yes" were "I'm in pain when I walk" and "I'm in pain when climbing up and down 
stairs or steps" $(42.5 \% ; \mathrm{n}=51)$. Thirty-two residents $(25.8 \% ; \mathrm{n}=31)$ stated not to be in pain at all and replied to all eight questions about pain with "no". Four residents answered all eight questions about pain with "yes".

The domain "Energy" had a mean score of $43.7 \pm 37.1$. The question most frequently answered with "yes" was "I soon run out of energy" (52.5\%; $n=63) .30 .0 \%(n=36)$ had no problems with their "Energy". 20.0\% ( $\mathrm{n}=24)$ answered all three questions about their "Energy" with "yes".

The highest score was discovered in the domain "Physical Mobility" with 53.5 (SD \pm 24.0 ). Over $50.0 \%$ of the residents answered five out of eight questions in this domain with "yes", i.e. "I need help to walk about outside" was answered with "yes" by 101 residents (84.2\%). Four residents had no problems at all with their "Physical Mobility" and answered all eight questions with "no", five residents answered all questions in this domain with "yes". An overview of all 38 questions answered with "yes" is given in Table 1.

\section{Univariate analysis}

The values of all HRQOL domains were not influenced by age ( $<85$ years vs. $\geq 85$ years; $p>0.05$ in all domains). With respect to gender, we found a difference in the domain "Pain", where, compared to male residents, women $(\mathrm{n}=85)$ had a significantly higher score (poorer HRQOL) (mean score women: $29.5 \pm 31.5$; males: $14.9 \pm 17.2 ; \mathrm{p}=0.011$ ) (Table 2).

Independent from the care dependency grade the highest score was found in the domain "Physical Mobility", followed by the domain "Energy". Residents with a low care dependency scored significantly lower (better HRQOL) in the domain "Sleep" than residents with a high care dependency (mean score 15.3; $\mathrm{SD} \pm 19.0$ versus mean score 32.8 $\mathrm{SD} \pm 33.2 ; \mathrm{p}<0.02)$. No other significance was detected (Figure 2).

\section{Multivariate regression analyses}

Table 3 summarizes the results of the regression analyses in terms of the standardized regression coefficients $B$ and p-values. For all six NHP domains regression analysis did not find any influence by age (regression coefficients $\beta$ between -0.017 for the domain "Pain" and 0.104 for the domain "Physical Mobility") with the exception of the domain "Pain", which was influenced by gender $(ß=-0.238$, $\mathrm{p}=0.015)$. HRQOL was not influenced by gender either. Care dependency had an impact on the domain "Sleep" $(B=-0.195, p=0.031)$, while the other domains were not affected by care dependency. Linear regression analysis therefore confirms the results of unvaried statistics.

In all regression models except for "Energy" and "Emotional Reaction", Durbin-Watson statistics were in an acceptable range between 1.6 ("Social Isolation") and 2.09 ("Sleep"), However the explanatory power of the regression models is weak: Only between $2 \%$ and $7 \%$ of the variation in the domains of HRQOL can be explained by age, gender and CDS. For this reason results should be interpreted with caution.

\section{Discussion}

This study presents results from eleven nursing homes in Germany about HRQOL from the resident's perspective, which according to Kane et al. denotes the "gold standard" [26]. Measuring HRQOL provides an outstanding insight towards approaches that may lead to an improved quality of care [27]. HRQOL was measured in six dimension of the NHP.

As a main result of our study we found that care dependency of the nursing home residents does not influence HRQOL of the residents, except for the domain "Sleep". Here, residents with a high care dependency, compared to those with a low care dependency, had a significantly lower HRQOL (mean score: high care dependency 32.8 vs. low care dependency 15.3, $\mathrm{p}=0.02$ ). This can be explained by the fact that high care dependency residents are in more need of care compared to other residents. Nurses, for example, have to check the residents during night for incontinence problems or to change positions to avoid pressures ulcer, which results in disturbed sleep.

All other HRQOL domains ("Energy", "Pain", Emotional Reaction", Social Isolation" and "Physical Mobility") both in the univariate and in the regression analysis showed no significant results in relation to care dependency. Therefore HRQOL in our setting does not seem to be influenced by the degree of care dependency which is comparable with the other studies in similar contexts $[28,29]$. It is worthy of note that the evaluation of HRQOL from the perspective of relatives, nurses or physicians does not necessary agree with the residents' perspective [28-30], which shows the importance of this specific feature. This is particularly important for elder people and their perception of getting older in a permanently developing environment. Thus, standards and values in this group of people are of great importance for the assessment of HRQOL [31]. Moreover, aspects of a "good" or "normal" HRQOL might therefore be subject to change in the various periods of elderly people's life compared to other patient groups [32].

Taking this into account the reasonable HRQOL in our setting is understandable. Almost all HRQOL scores were below fifty from a possible 100, the maximum was not reached. A literature search revealed results of adults discharged from hospitals to their own homes in Switzerland who had an even lower HRQOL in the domains "Emotional Reaction" (79.8) and "Social Isolation" (87.2) [33] compared to our results ("Emotional Reaction" mean score: 19.2 and "Social Isolation" mean 


\begin{tabular}{|c|c|c|c|}
\hline Domain & Item & Yes n (\%) & Missing $\mathrm{n}(\%)$ \\
\hline \multicolumn{4}{|l|}{ Energy } \\
\hline & I'm tired all the time & $41(34.2)$ & 0 \\
\hline & I soon run out of energy & $63(52.5)$ & 0 \\
\hline & Everything is a strenuous effort & $58(48.3)$ & 0 \\
\hline \multicolumn{4}{|l|}{ Pain } \\
\hline & I have pain at night & $24(20.0)$ & 0 \\
\hline & I find it painful to change position & $34(28.3)$ & $1(0.8)$ \\
\hline & I have unbearable pain & $13(10.8)$ & 0 \\
\hline & I'm in pain when I walk & $51(42.5)$ & 0 \\
\hline & I'm in pain when I'm standing & $46(38.3)$ & 0 \\
\hline & I'm in pain when I'm sitting & $29(24.2)$ & $2(1.7)$ \\
\hline & I'm constant pain & $26(21.7)$ & 0 \\
\hline & I'm in pain when going up and down staires or steps & $51(42.5)$ & $22(18.3)$ \\
\hline \multicolumn{4}{|c|}{ Emotional reaction } \\
\hline & Things are getting me down & $48(40.0)$ & 0 \\
\hline & I've forgotten what it's like to enjoy myself & $24(20.0)$ & $1(0.8)$ \\
\hline & I'm feeling on edge & $10(8.3)$ & 0 \\
\hline & The day seem to drag & $47(39.2)$ & 0 \\
\hline & I lose my temper easily these days & $17(14.2)$ & 0 \\
\hline & I feel as if I'm losing control & $7(5.8)$ & $1(0.8)$ \\
\hline & Worry is keeping me awake at night & $19(15.8)$ & $2(1.7)$ \\
\hline & I feel life is not worth living & $25(20.8)$ & $4(3.3)$ \\
\hline & I wake up feeling depressed & $20(16.7)$ & 0 \\
\hline \multicolumn{4}{|l|}{ Sleep } \\
\hline & I take tablets to help me sleep & $12(10.0)$ & 0 \\
\hline & I lie awake for most of the night & $22(18.3)$ & 0 \\
\hline & I'm waking up in the early hours of the morning & $48(40.0)$ & 0 \\
\hline & I sleep badly at night & $31(25.8)$ & $3(2.5)$ \\
\hline & It takes me long time to get to sleep & $31(25.8)$ & 0 \\
\hline \multicolumn{4}{|l|}{ Social isolation } \\
\hline & I feel lonely & $44(36.7)$ & $1(0.8)$ \\
\hline & I'm finding it hard to made contact with people & $33(27.5)$ & $1(0.8)$ \\
\hline & I feel there is nobody I am close to & $15(12.5)$ & $1(0.8)$ \\
\hline & I finding it hard to get on with people & $15(12.5)$ & $1(0.8)$ \\
\hline & I feel I am a burden to people & $24(20.0)$ & $3(2.5)$ \\
\hline \multicolumn{4}{|c|}{ Physical mobility } \\
\hline & I can only walk about indoors & $52(43.3)$ & 0 \\
\hline & I find it hard to bend & $80(66.7)$ & 0 \\
\hline & I'm unable to walk all & $8(6.7)$ & $1(0.8)$ \\
\hline & I have trouble getting up and down stairs or steps & $91(75.8)$ & $2(1.7)$ \\
\hline & I find it hard to reach for things & $59(49.2)$ & $1(0.8)$ \\
\hline & I find it hard to dress myself & $71(59.2)$ & $2(1.7)$ \\
\hline & I find it hard to stand for long & $98(81.7)$ & $1(0.8)$ \\
\hline & I need help to walk about outside & $101(84.2)$ & $1(0.8)$ \\
\hline
\end{tabular}


Table 2 Health-related quality of life measured with the Nottingham health profile according to the care dependency, gender and age of residents

\begin{tabular}{|c|c|c|c|c|c|c|}
\hline & $\begin{array}{c}\text { Energy } \\
\text { Mean (SD) }\end{array}$ & $\begin{array}{c}\text { Pain } \\
\text { Mean (SD) }\end{array}$ & $\begin{array}{c}\text { Emotional reaction } \\
\text { Mean (SD) }\end{array}$ & $\begin{array}{c}\text { Sleep } \\
\text { Mean (SD) }\end{array}$ & $\begin{array}{c}\text { Social isolation } \\
\text { Mean (SD) }\end{array}$ & $\begin{array}{c}\text { Physical mobility } \\
\text { Mean (SD) }\end{array}$ \\
\hline \multicolumn{7}{|l|}{ Care dependency } \\
\hline Low care dependency $(n=37)$ & $42.6(39.2)$ & $29.6(32.4)$ & $15.7(22.5)$ & $15.3(19.0)$ & $19.7(20.8)$ & $52.0(19.3)$ \\
\hline Moderate care dependency $(n=51)$ & $39.3(33.9)$ & $21.2(21.7)$ & $18.8(20.1)$ & $20.4(24.2)$ & $21.7(25.5)$ & $54.3(24.7)$ \\
\hline High care dependency ( $n=23$ ) & $49.5(40.5)$ & $27.1(33.9)$ & $23.6(26.8)$ & $32.8(33.2)$ & $22.9(33.5)$ & $57.1(25.3)$ \\
\hline p-value (ANOVA) & 0.549 & 0.367 & 0.418 & 0.030 & 0.883 & 0.712 \\
\hline \multicolumn{7}{|l|}{ Age } \\
\hline$<85$ years $(n=54)$ & $49.2(41.0)$ & $25.4(28.7)$ & $19.3(22.3)$ & $2 \underline{4} .7(29.5)$ & $22.8(28.6)$ & $52.7(24.5)$ \\
\hline$\geq 85$ years $(n=66)$ & $39.2(33.2)$ & $25.2(29.2)$ & $19.1(23.2)$ & $19.8(24.7)$ & $22.1(24.4)$ & $54.2(23.8)$ \\
\hline $\mathrm{p}$-value (T-Test) & 0.143 & 0.961 & 0.966 & 0.325 & 0.877 & 0.749 \\
\hline \multicolumn{7}{|l|}{ Gender } \\
\hline Female $(n=85)$ & $47.5(37.3)$ & $29.5(31.5)$ & $20.2(24.2)$ & $25.0(29.3)$ & $20.1(25.1)$ & $53.7(25.3)$ \\
\hline Male $(n=35)$ & $34.9(35.6)$ & 14.9 (17.2) & 16.8 (18.9) & 14.7 (12.6) & $28.0(28.5)$ & $52.9(20.8)$ \\
\hline $\mathrm{p}$-value (T-Test) & 0.091 & 0.011 & 0.456 & 0.057 & 0.137 & 0.867 \\
\hline
\end{tabular}

score: 22.4 ). Another study on hip fracture patients in all six domains of the NHP showed a lower HRQOL than our setting one week after hospital admission. [34]. This could be explained by the aforementioned aging process and also the process of moving into a nursing home which is usually not based upon an abrupt decision but rather as a result of severe and acute problems associated with a hospital admission.

Becoming aware of an increasing age goes alongside with cognitive and emotional adaptation processes resulting in a recalibration of individual goals and beliefs. In addition to internal standards and values, conceptualization and reconsidering of quality of life is also a part of the adaptation process $[35,36]$. As a consequence, HRQOL in our setting can be better compared to studies in acute settings.

The highest reduction of HRQOL was seen in the domains "Physical Mobility" (mean score 53.5) indicating clearly the residents' physical limitations. This is of course not surprising, as most nursing home residents prior to nursing home admission suffer from several chronic diseases leading to substantial physical dependency, which then becomes a predictor for admission to a nursing home $[37,38]$. However, the efforts made by residents to remain mobile use a lot of their energy, which is clearly reflected in the mean score of the domain "Energy" (43.7). In our

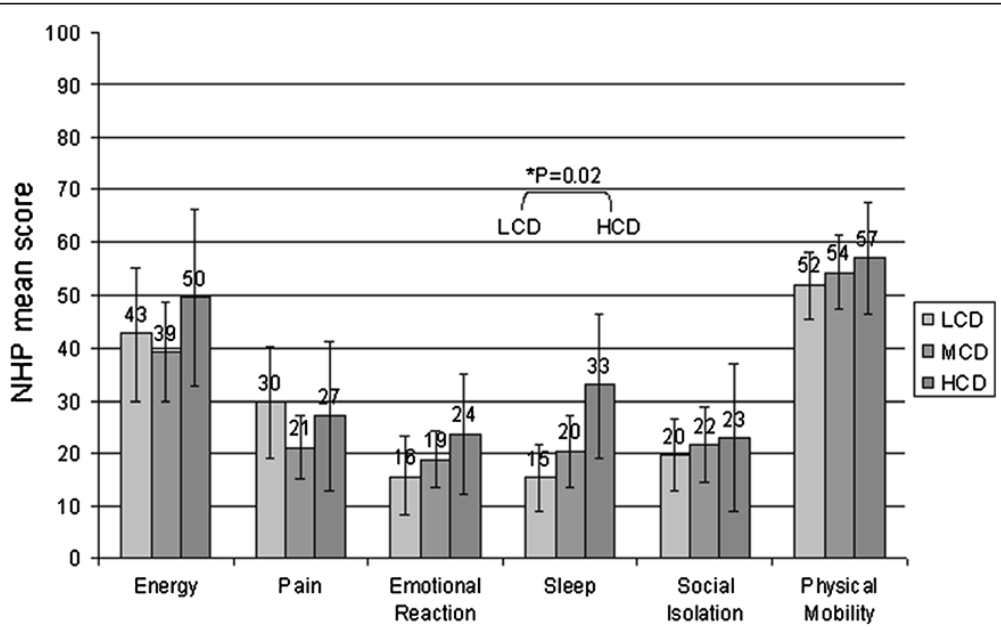

Figure 2 Care dependency Level according to Health related quality of life measured with the Nottingham Health Profile (NHP). $L C D=$ Low care dependency $(N=37)$. $M C D=$ Moderate care dependency $(N=51)$. $H C D=$ High care dependency $(N=23)$. 
Table 3 Multivariate regression analysis according to the influence of care dependency, age and gender on healthrelated quality of life measured with the Nottingham health profile

\begin{tabular}{llll}
\hline & Care dependency score & Age & Gender
\end{tabular}

Energy

$\begin{array}{lc}\text { Beta }[95 \% \mathrm{Cl}] & -0.075[-0.835,0.344] \\ \mathrm{T} & -0.825 \\ \text { Sig. } & 0.411 \\ \text { Pain } & \end{array}$

Pain

Beta $[95 \% \mathrm{Cl}]$

$\mathrm{T}$

Sig.

$0.029[-0.379,0.525]$

0.321

0.749

Emotional reaction

$\begin{array}{lc}\text { Beta }[95 \% \mathrm{Cl}] & -0.116[0.592,0.132] \\ \mathrm{T} & -1.260 \\ \text { Sig. } & 0.210\end{array}$

Sleep

Beta $[95 \% \mathrm{Cl}]$
T
Sig.

Social isolation

Beta $[95 \% \mathrm{Cl}]$
T
Sig.

Physical mobility

Beta $[95 \% \mathrm{Cl}]$

T

Sig.

$$
\begin{gathered}
-0.137[-0.670,0.094] \\
-1.492 \\
0.139
\end{gathered}
$$

Durbin Watson: 0.1691 R Quadrat: 0,030

$0.005[-0.830,0.872]$
0.049
0.961

Durbin Watson:1.798 R Quadrat: 0,055

$-0.017[-0.710,0.596]$
-0.173
0.863

Durbin Watson:1.141 R Quadrat: 0,026

$$
\begin{gathered}
0.094[-0.270,0.775] \\
0.957 \\
0.341
\end{gathered}
$$

Durbin Watson:2.089 R Quadrat: 0,069

$$
\begin{gathered}
-0.026[-0.689,0.524] \\
-0.2269 \\
0.788
\end{gathered}
$$

Durbin Watson:1.556 R Quadrat: 0,028

$$
\begin{gathered}
0.087\left[-0.332_{1 \prime} 0.875\right] \\
0.892 \\
0.374
\end{gathered}
$$

Durbin Watson:1.745 R Quadrat: 0,028

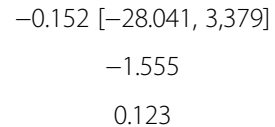

$-0.238[-27.074,-2.967]$

$-2.468$

0.015

$-3.343$

0.733

$-0.178[-21.765,0.624]$
-1.870
0.064

$0.168[-1.465,20.806]$

1.720

0.088

study, more than fifty-two percent of the residents state that they "run out of energy". One measure to improve this situation is to adapt exercise programmes which have already proven their effectiveness in other studies $[39,40]$.

HRQOL was independent from the care dependency in the domains "Pain", "Social Isolation", "Emotional Reaction", and "Sleep" with all mean scores being less than twenty five points. With respect to gender differences we only found a significantly lower HRQOL in women compared to men in the domain "Pain" (mean score 29.5 vs. 14.9, $\mathrm{p}=0.011$ ), which is confirmed by other studies $[41,42]$. An explanation might be that individuals who consider themselves more masculine and less sensitive to pain show higher pain thresholds and tolerances [42].

\section{Limitation}

Out of all residents $(n=553)$ agreeing to participate only $41.4 \%$ could be included in the NHP analysis, which has already been discussed in detail [18]. In addition to the sample size of our study it cannot be regarded as representative. This is mainly due to the fact that the drop out was not by random but by systematic conditions (residents declined to participate, data administration not possible, cognitive impairment). Moreover the sample was drawn in Berlin and Brandenburg (only two out of sixteen federal German states), so it can't be representative for nursing home residents "in general". Finally the residents were surveyed at the time of admission which also might have influenced their response. For the 
survey we chose the instrument NHP owing to the dichotomized response scale with a completion time of about 10 minutes. The high number of missing answers in the item "I'm in pain when going up and down stairs or steps" ( $n=22,18.3 \%)$ can be attributed to the use of elevators, to living on ground floors or to not being applicable to the resident's situation.

\section{Conclusion}

Overall, nursing home residents regard their own HRQOL as reasonable. Our study showed that the level of care dependency has no influence on the HRQOL from the nursing home residents' perspective except for the domain "Sleep". High care dependency residents have a lower HRQOL in this domain compared to moderate and low care dependency residents. It is still necessary to evaluate whether activities of nursing staff for high care dependency residents might be structured in such a way that exhaustion due to sleep disturbance is avoided. We found a significantly lower HRQOL in women compared to men in the domain "Pain". Gender aspects, too, should be examined in further studies. Most importantly the impact of aging processes in HRQOL should be made the subject of researches in a society that is growing older and older.

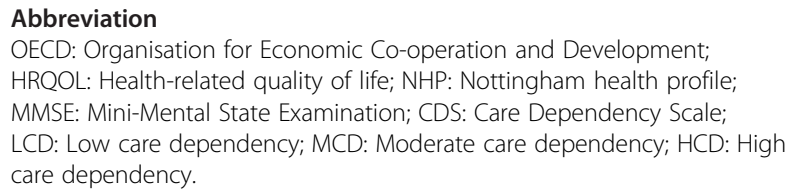

\section{Competing interests}

The authors declare that they have no competing interests. The research was not supported.

There is no financial relationship between the authors and any organisation.

\section{Authors' contributions}

MT participated in the design of the study and the performance of the statistical analysis and also drafted the manuscript. TO helped with the interpretation of the data, drafting or critical revision of the manuscript. EJ made substantial contributions to the interpretation of data and statistical analysis. TD agreed to the study and participated in its design. $\mathrm{CH}$ to approve of the study, participated in its design, coordination and critical revision of the manuscript. All authors have given final approval of the version to be published. All authors read and approved the final manuscript.

\section{Acknowledgements}

We would like to thank Mrs Dolenz for her contribution to editing the English version of this manuscript. Special thanks to all research assistants who collected all data.

\section{Author details}

'Department of Nursing Science, Charité- Universitätsmedizin Berlin, Augustenburgerplatz 1, Berlin 13353, Germany. Institute for Integrative Medicine, University of Witten/Herdecke, Gerhard-Kienle-Weg 4, Herdecke 58313, Germany. ${ }^{3}$ Scientific Institute of the medical insurance plan, Rosenthaler Straße 31, Berlin 10178, Germany. ${ }^{4}$ Protestant University of Applied Sciences Berlin, Teltower Damm 118, Berlin 14167, Germany.

Received: 13 August 2012 Accepted: 5 March 2013 Published: 11 March 2013

\section{References}

1. Organisation for Economic Co-operation and Development (OECD): The OECD Health Project Long-Term Care for Older People. 2005:140. ISBN 9264008489.

2. Akner $\mathrm{G}$ : Analysis of multimorbidity in individual elderly nursing home residents. Development of a multimorbidity matrix. Arch Gerontol Geriatr 2009, 49:413-419.

3. Lobo A, Santos P, Carvalho J, Mota J: Relationship between intensity of physical activity and health-related quality of life in Portuguese institutionalized elderly. Geriatr Gerontol Int 2008, 8:284-290.

4. Drageset J, Natvig GK, Eide GE, Clipp EC, Bondevik M, Nortvedt MW, Nygaard HA: Differences in health-related quality of life between older nursing home residents without cognitive impairment and the general population of Norway. J Clin Nurs 2008, 17:1227-1236.

5. United Nations Population Devision: World population prospects: The 2002 revision. 2003. ESA/P/WP.180.26 February 2003. http://www.un.org/esa/ population/publications/wpp2002/WPP2002-HIGHLIGHTSrev1.PDF.

6. Destatis: Demografischer Wandel in Deutschland - Heft 2 - Auswirkungen auf Krankenhausbehandlungen und Pflegebedürftige. https://www.destatis.de/DE/ Publikationen/Thematisch/Bevoelkerung/NorausberechnungBevoelkerung/ KrankenhausbehandlungPflegebeduerftige.html.

7. Dijkstra A, Buist G, Dassen T: Operationalization of the concept of "nursing care dependency" for use in long-term care facilities. Aust N Z J Ment Health Nurs 1998, 7:142-151.

8. Tu Y-C, Wang R-H, Yeh S-H: Relationship between perceived empowerment care and quality of life among elderly residents within nursing homes in Taiwan: a questionnaire survey. Int J Nurs Stud 2006, 43:673-680

9. Bavazzano A, Magnolfi SU, Calvani D, Valente C, Boni F, Baldini A, Quesada $\mathrm{JJ}$ : Functional evaluation of alzheimer patients during clinical trials: A review. Arch Gerontol Geriatr 1998, 26:27-32.

10. Dijkstra A, Brown L, Havens B, Romeren TI, Zanotti R, Dassen T, van den Heuvel W: An international psychometric testing of the care dependency scale. J Adv Nurs 2000, 31:944-952.

11. Cella DF: Quality of life outcomes: measurement and validation. Oncology (Williston Park) 1996, 10:233-246.

12. Németh G: Health related quality of life outcome instruments. Eur Spine J 2006, 15(Suppl 1):S44-51.

13. González-Salvador T, Lyketsos CG, Baker A, Hovanec L, Roques C, Brandt J, Steele C: Quality of life in dementia patients in long-term care. Int J Geriatr Psychiatry 2000, 15:181-189.

14. Menzi-Kuhn C: Lebensqualität von Menschen mit Demenz in stationären Langzeitpflegeeinrichtungen. University of Maastricht (NL) Faculty of Health, Department of Nursing; 2006.

15. PROQOLID, the Patient-Reported Outcome and Quality Of Life Instruments Database - Nottingham Health Profile (NHP) / Instruments / Home - eZ publish. http://www.proqolid.org/instruments/nottingham_health_profile_nhp.

16. Baró E, Ferrer M, Vázquez O, Miralles R, Pont A, Esperanza A, Cervera AM, Alonso J: Using the Nottingham Health Profile (NHP) among older adult inpatients with varying cognitive function. Qual Life Res 2006, 15:575-585.

17. McKenna SP, Hunt SM, McEwen J: Weighting the seriousness of perceived health problems using Thurstone's method of paired comparisons. Int J Epidemiol 1981, 10:93-97.

18. Tabali M, Jeschke E, Dassen T, Ostermann T, Heinze C: The Nottingham Health Profile: a feasible questionnaire for nursing home residents? Int Psychogeriatr 2011:1-9.

19. Lohrmann C, Dijkstra A, Dassen T: Care dependency: testing the German version of the Care Dependency Scale in nursing homes and on geriatric wards. Scand I Caring Sci 2003, 17:51-56.

20. Mertens E, Tannen A, Lohrmann C, Dassen T: Nursing care dependence in the hospital. A descriptive study. Pflege 2002, 15:195-201.

21. Folstein MF, Folstein SE, McHugh PR: "Mini-mental state". A practical method for grading the cognitive state of patients for the clinician. J Psychiatr Res 1975, 12:189-198.

22. Kempen Gl, Brilman El, Ormel J: The Mini Mental Status Examination. Normative data and a comparison of a 12-item and 20-item version in a sample survey of community-based elderly. Tijdschr Gerontol Geriatr 1995, 26:163-172.

23. International Classification of Diseases (ICD). http://apps.who.int/ classifications/icd10/browse/2010/en. 
24. Donner $\mathrm{A}$ : The relative effectiveness of procedures commonly used in multiple regression analysis for dealing with missing values. Am Statistic 1982, 36:378-381.

25. Durbin J, Watson GS: Testing for Serial Correlation in Least Squares Regression. I. Biometrika 1950, 37:409-428.

26. Kane RA, Kling KC, Bershadsky B, Kane RL, Giles K, Degenholtz HB, Liu J, Cutler L: Quality of life measures for nursing home residents. J Gerontol A Biol Sci Med Sci 2003, 58:240-248.

27. Spertus JA, Winder JA, Dewhurst TA, Deyo RA, Prodzinski J, McDonell M, Fihn SD: Development and evaluation of the Seattle Angina Questionnaire: a new functional status measure for coronary artery disease. J Am Coll Cardiol 1995, 25:333-341.

28. Horton R: Differences in assessment of symptoms and quality of life between patients with advanced cancer and their specialist palliative care nurses in a home care setting. Palliat Med 2002, 16:488-494.

29. Yi Z, Vaupel JW: Functional capacity and self-evaluation of health and life of oldest old in China. J Soc Issues 2002, 58(4):733-748.

30. Bowling A, Dieppe P: What is successful ageing and who should define it? BMJ 2005, 331:1548-1551.

31. Stevernik N, Timmer E: Das subjektive Alterserleben. Die zweite Lebenshälfte- Psychologische Perspektiven. Ergebnisse des Altersurvey. Bundesministerium für Familie, Senioren Frauen und Jugend, Verlag W. Kohlhammer. Band 2000, 195:451-484.

32. Rowe JW, Kahn RL: Successful aging. Gerontologist 1997, 37:433-440.

33. Cleopas A, Kolly V, Perneger TV: Longer response scales improved the acceptability and performance of the Nottingham Health Profile. J Clin Epidemiol 2006, 59:1183-1190.

34. Van Balen R, Steyerberg EW, Polder JJ, Ribbers TL, Habbema JD, Cools HJ: Hip fracture in elderly patients: outcomes for function, quality of life, and type of residence. Clin Orthop Relat Res 2001, 390:232-243.

35. Rothermund K, Brandtstädter J: Coping with deficits and losses in later life: from compensatory action to accommodation. Psychol Aging 2003, 18:896-905.

36. Schmidt SJ: Der Diskurs des Radikalen Konstruktivismus. 9th edition. Frankfurt (Main): Suhrkamp Verlag; 1987. ISBN 10: 3518282360.

37. Nygaard HA, Naik M, Ruths S: [Mental impairment in nursing home residents]. Tidsskr Nor Laegeforen 2000, 120:3113-3116.

38. Rothgang H, Kulik D, Müller R, Unger R: GEK Pflegereport 2009. Verlag Asgrad St. Augustin. ISBN 978-3-537-44073-0. https://presse.barmer-gek.de/ barmer/web/Portale/Presseportal/Subportal/Presseinformationen/Archiv/ 2009/091118-Pflegereport-2009/Content-Pflegereport-2009.html

39. Dechamps A, Diolez P, Thiaudière E, Tulon A, Onifade C, Vuong T, Helmer C, Bourdel-Marchasson I: Effects of exercise programs to prevent decline in health-related quality of life in highly deconditioned institutionalized elderly persons: a randomized controlled trial. Arch Intern Med 2010, 170:162-169.

40. Lee LYK, Lee DTF, Woo J: Tai Chi and health-related quality of life in nursing home residents. J Nurs Scholarsh 2009, 41:35-43.

41. Aberg AC: Gender comparisons of function-related dependence, pain and insecurity in geriatric rehabilitation. J Rehabil Med 2005, 37:378-384.

42. Alabas OA, Tashani OA, Tabasam G, Johnson Ml: Gender role affects experimental pain responses: A systematic review with meta-analysis. Eur J Pain 2012, 16(9):1211-1223.

doi:10.1186/1477-7525-11-41

Cite this article as: Tabali et al:: Does the care dependency of nursing home residents influence their health-related quality of life?-A crosssectional study. Health and Quality of Life Outcomes 2013 11:41.

\section{Submit your next manuscript to BioMed Central and take full advantage of:}

- Convenient online submission

- Thorough peer review

- No space constraints or color figure charges

- Immediate publication on acceptance

- Inclusion in PubMed, CAS, Scopus and Google Scholar

- Research which is freely available for redistribution

Submit your manuscript at www.biomedcentral.com/submit
Ciomed Central 